\title{
Sexualidad, política del cuerpo y función socioeducativa del cine en Touch Me Not (Adina Pintilie, 2018)
}

\author{
Sexuality, Body Politics and Socio-Educational Function of the \\ Cinema in Touch Me Not (Adina Pintilie, 2018)
}

\author{
Silvia Guillamón Carrasco \\ Universitat de València, España \\ silvia.guillamon@uv.es
}

Jorge Belmonte Arocha

Universitat de València, España jorge.belmonte@uv.es

\section{Resumen:}

Este artículo analiza la ópera prima de la cineasta Adina Pintilie, Touch Me Not (Nu mă atinge-mă, 2018), ganadora del Oso de Oro y del premio a la Mejor Ópera Prima en el Festival de cine de Berlín. En primer lugar, contextualizamos el texto fílmico, abordando su distanciamiento de la tradición del denominado "nuevo cine rumano" y su planteamiento estético híbrido, a medio camino entre el cine observacional y experimental. En segundo lugar, analizamos las tesis que el discurso fílmico plantea en su tematización de la sexualidad y el cuerpo. Para ello, nos servimos de la teorización freudiana de la sexualidad y la reflexión foucaultiana sobre el biopoder, siguiendo el planteamiento de Teresa de Lauretis (2008) de combinar a ambos autores. A lo largo del texto, abordamos la forma en que el cuerpo se convierte en un espacio desde el que pensar la relación entre lo individual y lo social, lo privado y lo público, la relación con el otro o con uno mismo. Finalmente, concluimos subrayando cómo, con una clara motivación política y socioeducativa, la película plantea un uso de una interpelación fílmica que pretende involucrar a los espectadores e implicarlos tanto intelectual como emocionalmente.

\begin{abstract}
:
This article analyses the opera prima by the filmmaker Adina Pintilie, Touch Me Not (Nu mă atinge-mă, 2018), winner of the Golden Bear and Best First Feature at the Berlin Film Festival. First, we look at the context of the film text, focusing on its detachment from the tradition of the so-called Romanian New Wave and its hybrid aesthetic approach, halfway between observational and experimental cinema. Secondly, we analyse the theses that the film discourse proposes in its thematization of sexuality and body. To do this, we use the Freudian theorization of sexuality and Foucaultian reflection on biopower, following Teresa de Lauretis' approach (2008) to combine the two authors. Throughout the text we address the way in which the body becomes a space from which to think about the relationship between the individual and the social, the private and the public, the relationship with the other or with oneself. Finally, we conclude by highlighting how, with a clear political and socio-educational motivation, the movie proposes a use of a filmic interpellation that, explicitly, tries to involve spectators both intellectual and emotionally.
\end{abstract}

Palabras clave: Sexualidad; psicoanálisis; política del cuerpo; interpelación fílmica; biopoder; cine socioeducativo.

Keywords: Sexuality; Psychoanalysis; Body politics; Filmic interpellation; Biopower; Socio-Educational cinema. 


\section{Introducción. Adina Pintilie en contexto}

La película Touch Me Not (Nu mă atinge-mă, 2018), de la cineasta Adina Pintilie, es una rara avis dentro del panorama del cine rumano del siglo XXI. Con nueve cortometrajes ${ }^{1} \mathrm{y}$ un mediometraje documental en su haber -Don't Get Me Wrong... (Nu te supăra, dar..., 2007)-, la directora ha obtenido con su primer largometraje dos de los galardones más relevantes en la $68^{\mathrm{a}}$ edición del Festival de cine de Berlín: el Oso de Oro y el premio a la Mejor Ópera Prima. Como proyecto fílmico, Touch Me Not tardó siete años en poder salir adelante, siendo finalmente el resultado de una co-producción entre Alemania, República Checa, Bulgaria, Francia y Rumanía.

Tras su paso por la Berlinale, la película de Pintilie ha recorrido numerosos festivales de cine, obteniendo un éxito creciente en la escena cinematográfica internacional: Nyon, Estambul, Moscú, Kiev, Cluj, Sydney, Bolonia, Toronto, Helsinky, Londres, Sevilla, Ámsterdam, etc. No obstante, Touch Me Not ha creado una gran controversia en la crítica internacional, que se debate entre la alabanza y la animadversión, la admiración y el desagrado ${ }^{2}$. En buena medida, la hostilidad de un sector importante de la crítica hacia la película parece una reacción contra el tipo de representación de la sexualidad y del cuerpo que el filme plantea. Aunque también parte del desconcierto de la crítica cinematográfica tiene que ver con la expectativa asumida de que la película fuera a seguir el estilo de la llamada "Nueva ola del cine rumano", una corriente que llegó a cosechar, al menos hasta el 2016, un éxito creciente en los festivales internacionales del nuevo siglo. Frente a las posturas más reticentes hacia la película3, la crítica de Carmen Gray (2018) defiende el

\footnotetext{
${ }^{1}$ Her (Ea, 2003); Nea Pintea... Model (2004); Unwatched Trains (Trenuri nesupravegheate, 2004); Some Kind of Loneliness (2005); The Fear of Mr. G. (Frica domnului G., 2005); Casino (2005); SandPitt\#186 (Balastierra\#186, 2007); Oxygen (2010) y Diary\#2 (2013).

2 Aunque parte de la crítica se mostró favorable ante la elección del filme de Pintilie en el Festival de Cannes, como bien ha apuntado Carmen Gray (2018), otros críticos interpretaron la decisión del Jurado como una apuesta política, vinculada deliberadamente con el movimiento \#MeToo. En este sentido, señala la autora, llama la atención la virulencia de algunas de estas críticas, como la vertida por Peter Bradshow (2018) en The Guardian, quien sarcásticamente calificó la elección del Jurado de catástrofe mundial (a la misma altura del Brexit o del triunfo de Donald Trump).

3 Para una mayor concreción y análisis del recorrido del filme de Pintilie por los festivales de cine, así como de su recepción por parte de la crítica, véase el artículo de Wang Yao (2018), "Adina Pintilie and the End of Romanian New Wave".
} 
valor añadido de un filme que, según la autora, difiere notablemente del estilo característico de la Nueva ola, llegando a plantear que la ópera prima de Pintilie supone una clara ruptura con esta tradición dentro del cine rumano. Sin embargo, como ha apuntado Yao (2018, p. 54) debemos tener en cuenta que la Nueva ola ya había mostrado síntomas de división muy tempranamente: “(...) it should be noted that Romanian New Wave has already split and changed several times over the past years since 2005. If one thinks from the point of view of film history, the changes have long been rooted in the very beginning”.

Encabezada por Cristi Puiu, cuyo debut en 2001 con Stuff and Dough (Marfa si banii) significó el inicio de esa "Nueva ola", la generación de directores que renovaron la escena cinematográfica rumana -entre los que se sitúan Corneliu Porumboiu, Cristian Mungiu, Cristian Nemescu, Cătălin Mitulescu, Radu Muntean, o Călin Peter Netzer- asume, a través de la representación fílmica, una reescritura del pasado. Un grupo de cineastas que irrumpe en el recién entrado siglo XXI y que recurre al realismo cinematográfico con la misma pasión que lo hicieron sus predecesores (Lucian Pintilie, Dan Pita, Mircea Veroiu o Mircea Daneliuc), quienes previamente ya habían iniciado el camino de la ruptura con el realismo socialista.

Pero a diferencia de ellos, los miembros de esta generación acuden al realismo bajo una mirada diferente, lo suficientemente idiosincrática como para determinar el nacimiento de una nueva etapa en el desarrollo del cine rumano: "Este grupo de jóvenes airados -con este nombre se aludía a los integrantes del Free cinema- como aquellos que renovaron el cine en los años 60 y 70, van a ajustar cuentas con el pasado y a mostrar una realidad que había sido encubierta por la historia oficial” (Ayuso Ros, 2014a, p. 6). En este sentido, la Nueva ola hace suyo el "estilo observacional" con una cierta poética de vanguardia y experimentación (Ieta, 2010; Pop, 2014; Popan, 2014), para plantear su crítica a la sociedad de los ochenta y la dictadura de Ceaușescu a partir de una fuerte carga de humor negro, basado en el recurso a la ironía verbal y visual (Nasta, 2016). 
De esta tradición temática y estética parece desviarse el filme de Pintilie, cuya obra podría ser sintomática, tal como ha señalado Yao (2018), del inicio de la era post-Nueva ola. Algo que el autor plantea como una posibilidad, vinculada al impulso de la generación de cineastas nacidos en los años ochenta, cuya gradual liberación de las metodologías de la Nueva ola podría estar apuntando en esa dirección:

In the meantime, we see the rise of a new generation along with the renaissance of film industry. Directors who were born in the 1980 s came onto the stage. Of course, Adina Pintilie receiving the trophy for Best Debut from jury president Călin Peter Netzer was a symbol of inter-generation turnover, but it is still too early to announce a "new-new wave". However, one thing is certain. They would gradually liberate of the impact of Romanian New Wave methodologies, when they start to make their first or second feature films (Yao, 2018, p. 57).

De hecho, el filme de Pintilie se aparta del énfasis en el contexto postCeauşescu y de la reflexión en torno al pasado, dejando atrás dos de las más reconocibles características de la Nueva ola. En este sentido, diversos elementos apuntan a un contexto cultural alejado de Rumanía. Frente a la presencia de actores y actrices rumanos y al uso de la lengua rumana, el rodaje en lengua inglesa o la presencia de un elenco internacional de intérpretes en el reparto 4 supone una desviación significativa de esa tradición.

Por otra parte, el alejamiento del contexto socio-histórico rumano podría explicar también la diferente manera de abordar ciertas cuestiones. Como veremos en el análisis, el filme de Pintilie se propone investigar cuestiones referidas a la política sexual, el cuerpo y la identidad en el siglo XXI. En esa exploración se introduce la terapia como un elemento central de la representación lo que, consecuentemente, permite localizar parte de la acción en un hospital. En esta tesitura, resulta llamativa la ausencia de personal

\footnotetext{
4 La película cuenta con la participación del activista alemán Christian Bayerlein y los terapeutas sexuales Seani Love y Hanna Hoffman (de Australia y Alemania respectivamente). Los actores y actrices profesionales que componen el resto del reparto son: la inglesa Laura Benson, el islandés Tómas Lemarquis, la búlgara Irmena Chichikova y los alemanes Dirk Lange y Hermann Mueller.
} 
sanitario en el filme, lo que se contrapone con la jerarquía plasmada en las películas de la Nueva ola, donde el cuerpo médico representa una élite insensible ante el sufrimiento del ciudadano común. Otro elemento destacable, en esta misma línea, estaría constituido por la asepsia del blanco empleado en la iluminación y la puesta en escena, que contrasta con la representación del espacio en el Nuevo cine rumano, cuyo énfasis en las superficies mugrientas y decadentes aparecen simbólicamente asociadas a la representación de la sociedad post-dictatorial.

A pesar de estos desviamientos, Touch Me Not no supone un desarraigo completo de algunos de los elementos estilísticos más característicos de la Nueva ola: el estilo observacional, el minimalismo en la puesta en escena, el uso de planos-secuencia, los planos de seguimiento, la composición horizontal del cuadro o el sonido diegético serían algunos rasgos que conectarían la obra de la directora con esa tradición.

En este sentido, la propuesta de Pintilie parece estar vinculada con ese tipo de mirada observacional y minimalista que renuncia explícitamente a la espectacularización y propone un modo enunciativo en el que la cámara se coloca a una cierta distancia de los personajes. No obstante, la película también exhibe su singularidad al integrar, como parte identitaria de un estilo que podemos calificar de híbrido (entre el estilo observacional y la experimentación), el especial uso del sonido extradiegético, un elemento cuya ausencia es considerada definitoria del minimalismo de la Nueva ola, tal como han señalado Uricaru (2019) o Nasta (2013; 2019). Así mismo, otros elementos presentes en el filme, como la interpelación explícita a cámara, el montaje disruptivo o el énfasis en una visualidad háptica (Marks, 2000), estarían apuntando a una desviación de la tradición del cine observacional y haciendo explícito su carácter experimental.

\section{Marco teórico y metodología}

En las próximas páginas nos proponemos analizar Touch Me Not, en primer lugar, desde un punto de vista estético, ahondando en su carácter híbrido y 
fronterizo, en su resistencia a todo intento de categorización, en su configuración como texto fílmico que se debate entre el documental observacional y el cine experimental. En segundo lugar, nos proponemos analizar las tesis que el discurso fílmico plantea en su tematización de la sexualidad y del cuerpo como conceptos problemáticos, como espacios asociados al trauma y al displacer, a la fantasía y al deseo, a la pulsión y al inconsciente, como espacios bisagra desde los que pensar la relación entre lo individual y lo social, lo privado y lo público, el yo y el otro o, incluso, la misma relación del individuo consigo mismo.

La lectura que ofrecemos del filme de Pintilie transita entre la teorización freudiana de la sexualidad y la reflexión foucaultiana del biopoder, dos teorías que han sido leídas habitualmente, como indica Teresa de Lauretis (2008), como opuestas e incompatibles, fruto, entre otras cosas, de interpretaciones sesgadas y parciales de ambos autores5. A partir de esta reflexión, nos proponemos en este artículo mostrar cómo la complementariedad entre ambas aproximaciones teóricas en la consideración de la sexualidad y el cuerpo aparecen expresadas en el texto fílmico que analizamos. Esto nos permitirá entender la manera en que Touch Me Not se presenta como un discurso fílmico que se interroga acerca de la sexualidad en un sentido complejo y amplio, enfocado en la constitución de un sujeto encarnado (embodied) que es, a la vez, psíquico y social. En relación con esto, defendemos que el filme, como constructo socio-cultural, también se plantea su propio carácter discursivo, haciendo manifiesta su voluntad de intervención social, educativa, política y ética, interpelando a los espectadores y explicitando su propósito de remover conciencias.

\footnotetext{
5 Especialmente en el caso de Freud, la autora explica que su obra ha sido erróneamente interpretada en el ámbito anglosajón, fruto de la traducción, desde el original alemán al inglés, que se ha hecho de un texto fundamental: "Triebe und Triebschickale" de 1915, traducido como "Instincts and their visicitudes", lo que ha conducido a malentendidos semánticos de largo alcance. Como señala la autora, el concepto de pulsión (Triebe), fundamental en la teoría de la sexualidad freudiana y en su concepción de la psique, ha sido traducido aquí como instincts (instintos) -otorgándole a la pulsión un carácter meramente innato- cuando, en realidad, Freud distinguió las pulsiones (Trieb) de los instintos (Instinkte).
} 


\section{Entre el documental observacional y la experimentación formal}

La obra de Pintilie se encuentra vinculada con su formación como directora en la UNATC (Universidad Nacional de Teatro y Cinematografía I.L. Caragiale), que cuenta con una larga tradición de "cine observacional", un subgénero cinematográfico que se plantea establecer un discurso fílmico en el que la cámara funcione como un mero observador, como un aparato de captura de la realidad y cuyo rol se encuentra limitado por una vocación puramente mostrativa. Esta corriente documental se propone rehuir de las técnicas tradicionales de la narración cinematográfica (tales como la intervención de la voz enunciadora, la sintaxis causal o el montaje narrativo) para favorecer la observación del evento profílmico y una edición basada en la continuidad espacio-temporal. Como bien ha señalado Bill Nichols (2013, p. 202), el documentalista observacional adopta una postura de no intervención, "un modo peculiar de presencia 'en la escena', en la que parece ser invisible y no participativo".

Si bien Touch Me Not trabaja con algunos elementos del "cine observacional", como pueda ser el afán investigador sobre el tema a tratar, la renuncia a la espectacularización cinematográfica o la estaticidad de la cámara, entendida como instrumento de registro de la realidad, lo cierto es que la propuesta estética y discursiva de Pintilie se propone, en gran medida, romper con esa tradición de la que parte. No en vano, la impronta experimental de la película, que cuestiona los fundamentos de la corriente observacional, deriva de la misma concepción del objeto fílmico como parte de un proyecto artístico más amplio, un proyecto que incluye una instalación de video para museos y un espectáculo de teatro interactivo interpretado por actores y actrices de la película.

Revisemos, a continuación, el argumento del filme, para pasar después a analizar los elementos de la puesta en escena y del montaje que supondrían una disrupción con ciertos postulados del cine observacional, haciendo de este poliédrico texto fílmico un objeto que rompe las barreras entre el género documental y la experimentación formal. 
Touch Me Not tematiza la paradoja del sujeto que se debate entre el miedo a establecer contacto físico con el otro y el deseo de disfrutar del roce, la sexualidad y la unión con el otro. El filme se presenta como una forma de auto-terapia en la que la directora pone en escena el proceso de investigación que ha seguido para formar su documental. En primera instancia, Pintilie parte de las entrevistas realizadas a Laura que, interpretada por la actriz Laura Benson, representa a una mujer que expresa un rechazo visceral ante el acercamiento físico: rehúsa ser tocada, pero no sabe por qué, desconoce el motivo exacto de dicha repulsa.

A lo largo del filme, diversas historias y personajes se irán introduciendo: algunos de ellos estarán involucrados en la terapia de Laura; otros aparecerán implicados en un proceso de terapia diferente, aunque relacionado con la dificultad de expresar emociones y establecer contacto con el otro. En esta amalgama de personajes, la directora acabará incluyéndose a sí misma como parte integrante de la investigación.

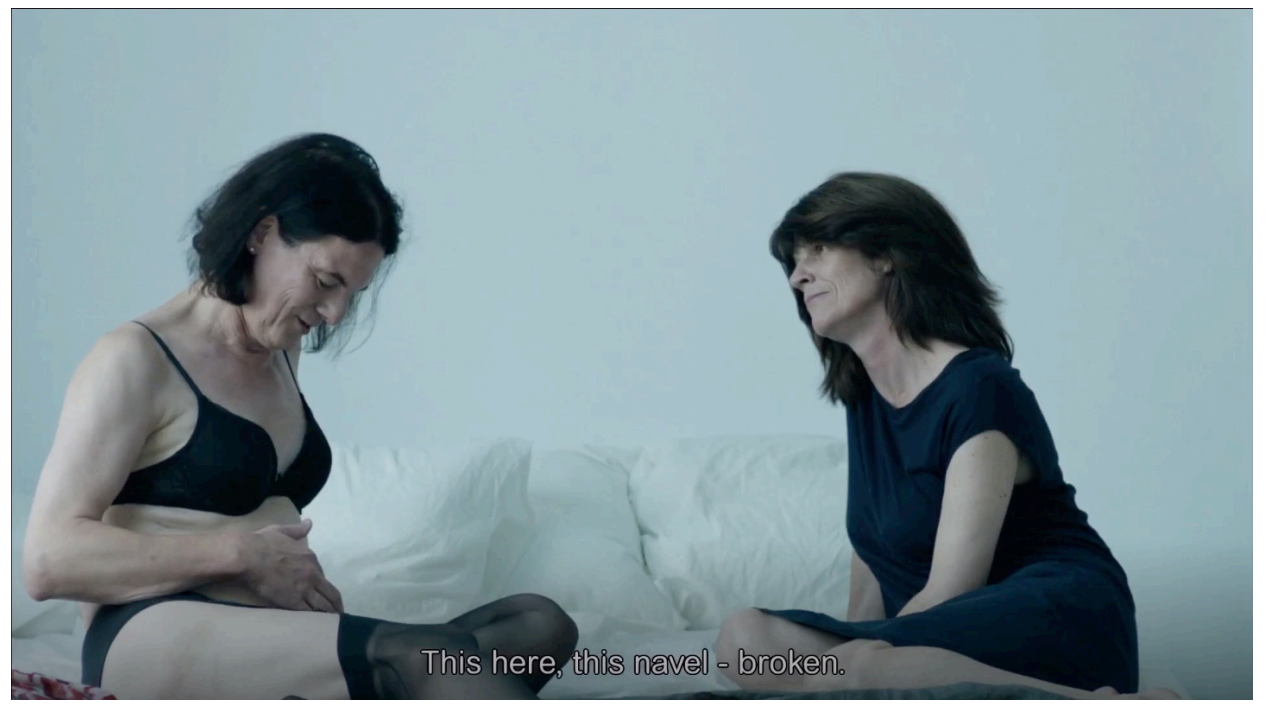

F1. Adina Pintilie, Touch Me Not (2018)

Veamos con más detalle cómo se desarrollan todas estas historias en el documental. La película comienza con la historia de Laura, quien relata cómo, para enfrentarse a su problema, decide contratar primero a un trabajador sexual (con quien no tiene sexo) y, después, buscar ayuda en dos terapeutas sexuales: Luxury Hanna (interpretada por Hanna Hoffman), trabajadora sexual transgénero (F1) y Seani (interpretado por Seani Love), 
especialista en terapia BDSM consciente (counscious kink). Mientras recibe la terapia, Laura visita a su padre en el hospital, donde se encuentra ingresado en la UCI. En ese mismo hospital asistimos a un taller de terapia del tacto (touch therapy workshop) que incluye personas con diversidad funcional y personas que desean mejorar sus relaciones. En este grupo se integran otros dos personajes importantes del filme, que son emparejados en la terapia: Tudor (interpretado por el actor Tómas Lemarquis), que tiene problemas para expresar sus emociones; y Christian, interpretado por Christian Bayerlein, un activista que tiene atrofia muscular espinal. El problema de Laura, como se descubre hacia el final del filme, parece haber sido originado en su infancia, causado por haber sufrido abusos sexuales por parte de su padre.

\subsection{Distancia e implicación}

La película integra en el mismo título, Touch Me Not, la contradicción del sujeto entre el deseo de ser tocado y el miedo a esa intimidad. El título alberga, en el uso imperativo del lenguaje, el fuerte contraste entre dos posiciones que se revelan incompatibles, una duplicidad entre la afirmación y la negación, entre la querencia y el rechazo. Estos dos elementos aparecen alterados en el título en inglés, donde la afirmación aparece en primer lugar, revelando una posición privilegiada en la construcción sintáctica. Contrariamente, en el título original en rumano -Nu mă atinge-mă ("No me toques/tócame”)-, la negación y, por tanto, el trauma, la herida del sujeto, se posiciona en primera instancia, frente al deseo de superación del trauma, que se revela como un segundo momento, una fase posterior y consciente del sujeto.

El filme se sitúa en esa ambigüedad de plantear su distancia respecto al hecho grabado y, al mismo tiempo, de involucrarse en las experiencias y las historias de los personajes. En tanto el cine de observación hace hincapié en la no intervención de la persona realizadora, en este caso, la distancia se proporciona a partir del estatismo de la cámara que, situada frente a los personajes, parece neutralizar cualquier tipo de disposición subjetiva. Con esta estrategia de distanciamiento, el cine observacional propone una mirada 
reflexiva, lo que implica "un posicionamiento ético por parte de la enunciación y una consideración del papel del espectador mucho más respetuosa" (Ayuso Ros, 2014b, p. 24). Esa mirada reflexiva, que facilita una participación activa del sujeto espectador, se favorece en el filme de Pintilie gracias a una planificación en la que se apuesta por la distancia de la cámara respecto a los personajes. De este modo, la captación de la intimidad se aborda desde una postura ética que renuncia a la espectacularización y al énfasis en los aspectos dramáticos. A esto se suma el particular uso que la directora hace del blanco en la puesta en escena, color que connota la asepsia de la modalidad terapéutica y, en este sentido, la toma de distancia de la persona investigadora.

Ahora bien, si bien el filme de Pintilie hace uso de estos elementos característicos del modo observacional, desde un primer momento se desmarca de la neutralidad asociada a dicha modalidad para cuestionar su supuesto afán de imparcialidad, planteando la problemática -y las trampas discursivas- de la transparencia enunciativa. De este modo, el filme nos presenta personajes que hablan a la cámara, interpelan directamente a la directora y, también, como veremos, a los espectadores. Por otra parte, la película exhibe, de principio a fin, el lugar de la producción, haciéndonos ver el carácter construido del propio discurso fílmico, evidenciando la subjetividad que se encuentra implicada en todo acto de escritura fílmica. El protagonismo de ese espacio discursivo se encarna en la presencia de la cámara, los caballetes o el equipo de rodaje a lo largo del documental. Así, en una de las primeras secuencias se nos muestra cómo el equipo monta la cámara que va a registrar la entrevista que Pintilie realiza a Laura. En ese preciso momento, aparece en escena, por primera vez, la directora del documental, identificada plenamente con el objetivo de la cámara, con el lugar desde el que se va a producir ese 'recorte de la realidad': el lugar de la enunciación y la construcción del tejido discursivo. De este modo, Pintilie se posiciona en el lugar privilegiado de la enunciación, el lugar desde el cual se nos va a mostrar/narrar lo que está aconteciendo ante nuestra mirada. 
La presencia de la directora, cuya mirada parece interpelarnos desde el principio, evidencia no solo una clara voluntad auterista, sino también un afán de posicionarse dentro de la escena como un personaje más. En distintos momentos del documental, como el que se representa en este plano (F2), Pintilie es introducida en el relato. Ella misma se coloca en una posición que acaba borrando las fronteras entre su rol como directora-entrevistadora y su papel como personaje-entrevistado.

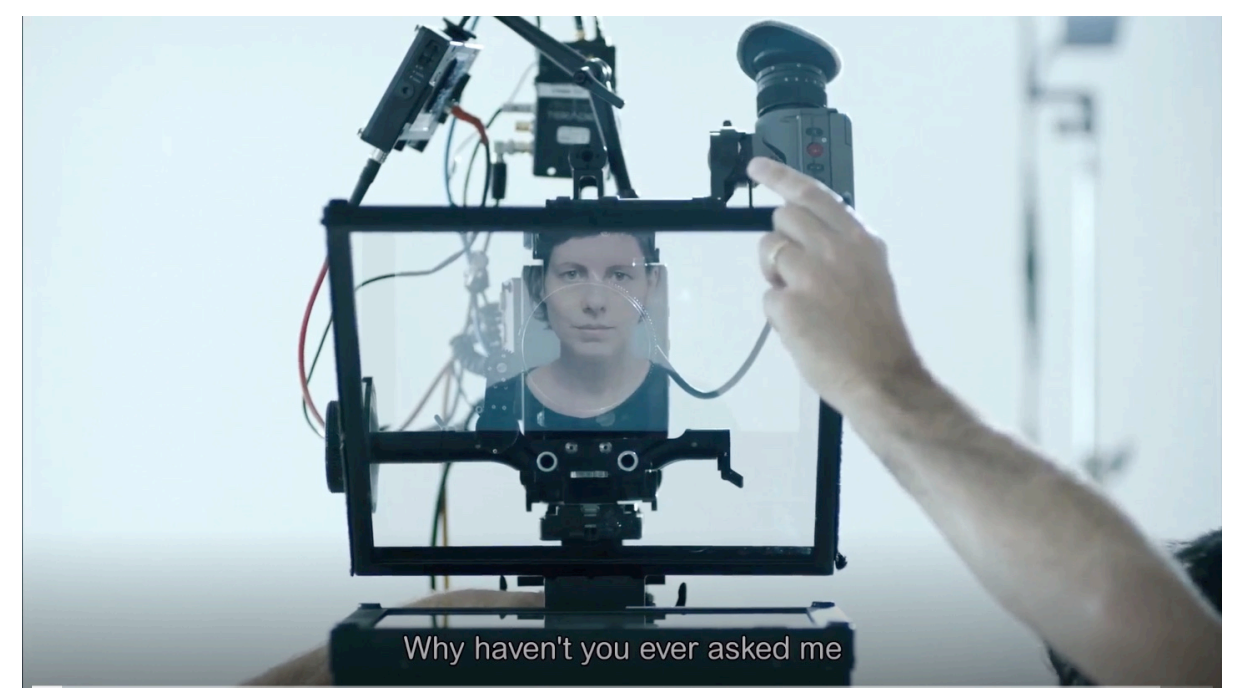

F2. Adina Pintilie, Touch Me Not (2018)

Desde un primer momento, las preguntas que Adina dirige a sus entrevistados parecen ir también dirigidas hacia sí misma, haciéndonos partícipes de la dificultad de comprender ciertos fenómenos relativos a la relación de pareja, la sexualidad o la relación con su madre. Fenómenos que, aparentemente diversos, parecen tener cierta conexión, aunque ésta no sea evidente para ella, como tampoco lo es para los espectadores. Así sucede cuando accede a intercambiarse por Laura, en su papel de entrevistadoraentrevistada, situándose como un personaje más que expone su problemática y nos abre las puertas a su intimidad. Sin embargo, a diferencia de los demás personajes, en esta secuencia se desvela el reto que le supone, como directora que tiende a situarse en una zona de confort detrás de las cámaras, relatar sus experiencias frente al aparato de filmación. 


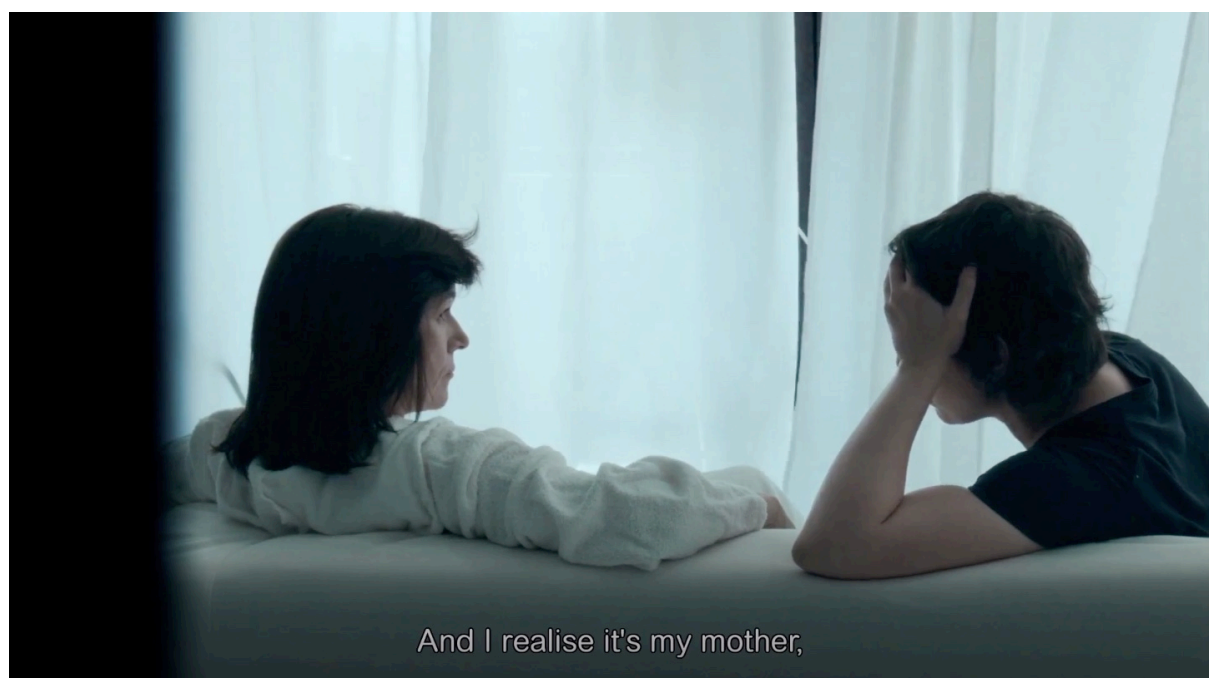

F3. Adina Pintilie, Touch Me Not (2018)

Más adelante, en otra secuencia, en la que aparece con Laura, ambas sentadas en un sofá de espaldas a la cámara (F3), nos hace partícipes de su intimidad: Adina relata un sueño que le resulta extraño e inquietante, en el que sitúa a su madre y a su propia pareja en una escena con claras connotaciones sexuales. Pero al hacerlo, la directora no oculta su pudor: se reserva, para esta secuencia, una retórica del distanciamiento, no solo por no situarse frente a la cámara, sino también por utilizar, aunque sutilmente, un montaje desincronizado. Un montaje en el que imagen y sonido no se corresponden, que pone en entredicho la inmediatez del desvelamiento y que, en definitiva, favorece la distancia espectatorial crítica respecto a lo narrado.

\subsection{Un montaje disruptivo}

Hablar del carácter experimental de Touch Me Not implica necesariamente abordar tres elementos fundamentales que componen su retórica audiovisual y que se encuentran indisolublemente vinculados: el uso del sonido, la presencia de una visualidad háptica y la construcción discursiva derivada del montaje. A diferencia del cine observacional, en el que se registra únicamente el sonido ambiente, rechazando toda incursión sonora que emane de la postproducción, la propuesta de Pintilie introduce el sonido extradiegético para generar determinados efectos, evocar una cierta sensorialidad y provocar respuestas emocionales en los espectadores. Pero no estamos ante una 
utilización de lo sonoro en función de estrategias narrativas convencionales, más bien al contrario: los sonidos en el filme evocan extrañeza y desapego, pueden provocar un cierto malestar, una incomodidad por su aparente disposición caótica en su relación con la imagen. Son sonidos que acompañan a las imágenes figurativas, pero apelan a una cierta abstracción, sonidos que generan emociones encontradas entre el afán interpretativo del espectador y la dificultad de reconocimiento.

Esa evocación sonora se ve reforzada por la presencia de lo háptico, un aspecto característico del videoarte, del cine feminista y de la experimentación formal con la percepción y la representación de la sexualidad (Marks, 2000). Centrada en la expresión sensorial de la imagen, la visualidad háptica supone una ruptura con la omnipotencia de la mirada y las formas voyeristas del cine hegemónico. En este sentido, la experimentación formal con imágenes granulosas, desenfoques o planos detalle favorecería la plasmación visual de un mundo sensorial y corpóreo que vendría a proporcionar una experiencia espectatorial más holística (Sobchack, 2004).

La impronta experimental de Touch Me Not pasa por atender a esa materialidad fílmica, con un énfasis especial en los planos detalle que nos acercan a una representación de lo corpóreo. El inicio del filme es, en este sentido, toda una declaración de intenciones: la cámara recorre lentamente un cuerpo masculino desnudo. Horizontalmente recortada por un plano detalle, la imagen transita entre el desenfoque del conjunto y la nitidez de los pequeños detalles. La porosidad de la piel, la suavidad del vello o la presencia de unos dedos que descansan sobre el pecho destacan sobre ese fondo borroso. El uso del plano detalle, que se debate entre la mostración figurativa y la tendencia a la abstracción, involucra intelectualmente al espectador, incitándole a adoptar una postura activa y reflexiva.

En este caso, la extrema cercanía con que la imagen es mostrada hace emerger lo háptico, aunque la descontextualización de la imagen acaba provocando un distanciamiento de esa intimidad que se nos ofrece. Un efecto que viene apuntalado también por la perspectiva en primer plano del sonido 
extradiegético, cuya evocación del aparato respiratorio nos hace partícipes de la materialidad física del cuerpo.

Ciertamente, el sonido no es aquí un lenguaje fácilmente decodificable, está descontextualizado y, en ocasiones como la mencionada, parece apelar a lo meramente corporal: la caja torácica, la respiración, el aliento.

A lo largo de la película, la banda sonora del grupo musical alemán Einstürzende Neubauten, incrustada en las imágenes de los personajes y del espacio filmado, resulta a la vez extraña y familiar. Escuchamos fragmentos de la canción "5:48 Uhr Tier”, que nos remiten a una etapa pre-lingüística, pero también a esa materialidad corporal que nos acompaña durante toda nuestra vida: exhalaciones, quejidos, suspiros, significantes sonoros sin referente alguno. Ese sonido se mezcla con otros: un tarareo ("mela-mela", extraído del estribillo de la canción "Die Befindlichkeit des Landes”) que surge en diversas secuencias asociadas al personaje de Laura y que se irá sustituyendo por pequeños fragmentos de la canción que, insertados a modo de leit motiv, simbolizan la paulatina adquisición de conciencia de la protagonista.

En consonancia con esto, el montaje se presenta como un elemento más de disrupción narrativa. Desmarcándose nuevamente del cine observacional, Pintilie adopta un montaje abrupto, seco, donde el corte se hace evidente, así como la discontinuidad entre una secuencia y la siguiente. Emerge, así, la materialidad del texto, la composición de la imagen, la sintaxis fílmica, el trabajo que existe detrás de todo discurso fílmico. La construcción del objeto fílmico se hace patente: como el mismo lenguaje, que ensambla elementos separados para componer una estructura significante, el montaje compone en un todo, fragmentos que, anteriormente, han sido filmados por separado.

\section{Lectura psicoanalítica}

\subsection{El trauma y la hipótesis represiva}

Touch Me Not se plantea, desde el principio, como un trabajo de investigación que se propone responder a cuestiones en torno a la sexualidad, 
la intimidad y el cuerpo. Pero la directora no expone con claridad la pregunta que le ha llevado a realizar la película. En el inicio de la entrevista con Laura, Adina confiesa que su necesidad investigativa parte de algo que ni siquiera ella misma alcanza a comprender, algo que no puede expresar con palabras porque parece haberse gestado en una etapa pre-lingüística de su vida y a lo que solo tiene acceso en los sueños, tal como declara: "I think it's because it's not in the words area. It comes from earlier on (...) Sometimes I have access to that in my dreams". También Laura sabe que tiene un problema ("90\% of me wants to hide"), pero desconoce los motivos de su trauma, del rechazo al contacto físico con el cuerpo masculino.

El planteamiento de lo indecible -en ambos casos vinculado a un problema con el cuerpo y la sexualidad-se relaciona con la idea de trauma, represión e inconsciente, aspectos todos ellos que nos remiten a la configuración psíquica del sujeto, en términos específicamente psicoanalíticos. Nos proponemos, a continuación, exponer la forma en que estas nociones han sido desarrolladas en la teoría freudiana, dando lugar a la hipótesis represiva del sujeto, y analizar la forma en que emergen en el texto fílmico a través de los personajes de Laura y Adina. Para ello, comenzaremos exponiendo una idea que atraviesa, según Laplanche y Pontalis (2004), la teoría freudiana: la conexión entre el trauma psíquico, la sexualidad y la teoría de la seducción infantil.

Como bien ha señalado Teresa de Lauretis, el concepto de trauma en Freud está enfocado hacia procesos intrapsíquicos que normalmente involucran al inconsciente. Se trata de una brecha en la proyección mental de la superficie del cuerpo, una brecha causada por una acción externa al individuo que provoca una alteración en el funcionamiento del aparato psíquico y causa en el yo una defensa patológica:

Trauma, Freud wrote in Beyond the Pleasure Principle (1920), is a breach in the protective shield of the human organism, the mental projection of the body's surface, that 'provoke[s] a disturbance on a large scale in the functioning of the organism's energy and [sets] in motion every possible defensive measure (de Lauretis, 2008, p. 4). 
En el Diccionario de psicoanálisis, Laplanche y Pontalis (2004) apuntaban cómo el concepto de trauma en la teoría freudiana se encuentra estrechamente vinculado con su teoría de la seducción infantil y su investigación sobre la histeria. La escena de la seducción, que para Freud incluiría acciones adultas con una dimensión sexual tanto intencionada como inintencionada ${ }^{6}$, que derivarían en una defensa represiva de la psique del sujeto, convirtiendo esos recuerdos en inconscientes y, por ende, creando y manteniendo síntomas histéricos. Una de las derivaciones sintomáticas del trauma se encuentra estrechamente relacionada con lo que Freud denominó Todestrieb, traducida como "pulsión de muerte", que, como indica de Lauretis, "no se trata del deseo de morir, sino más bien de la incapacidad de desear o de sentir placer, quizá de la incapacidad de vivir en el propio cuerpo" (2012, p. 10) Se trata de una experiencia traumática y que, como tal, tiene efectos directos sobre el cuerpo, pues produce un claro displacer, pero lo que la caracteriza es que es inconsciente: el sujeto padece el síntoma, pero no sabe por qué le pasa, no puede acceder fácilmente al origen de dicho trauma porque ha sido reprimido en su psique. Lo que plantea la película de Pintilie, en relación con el personaje de Laura, se encuentra estrechamente vinculado con esta idea: a la protagonista le repugna ser tocada, le provoca agresividad y un rechazo visceral.

La paradoja se encuentra en la colisión entre su deseo heterosexual, que es consciente, y la pulsión de muerte (Todestrieb), que es inconsciente y displacentera, lo que acaba derivando en una incapacidad para establecer el contacto corporal con el sujeto masculino, sintiéndose segura únicamente en la fantasía voyerista que establece con su objeto de deseo. Así, en la primera secuencia del filme, en una escena despojada de la espectacularización y del erotismo característico del cine hegemónico, vemos cómo Laura,

\footnotetext{
${ }^{6} \mathrm{El}$ trauma en Freud tiene distintos niveles de intensidad en la psique. El más grave es el causado por una acción intencionadamente sexual por parte de un adulto (como los abusos sufridos por Laura en la película). Pero el trauma tiene una dimensión más habitual a la que Freud también apunta: las acciones de la persona cuidadora (normalmente, la madre) sobre el cuerpo del bebé, acciones necesarias, como el amamantar, el lavar, el acariciar, etc. Se trata de acciones sensoriales que provocan excitación en el organismo y quedan como huellas mnémicas en el inconsciente del sujeto. Estas huellas aparecen después, en la vida adulta, en forma de fantasías inconscientes en los sueños. Este podría ser el caso de Adina en la película cuando relata el sueño que le resulta inquietante.
} 
enfrentándose a su problema, con una mirada a medio camino entre la terapia y la curiosidad, observa el cuerpo de un hombre desnudo en la ducha. Pronto sabremos que se trata de un trabajador sexual a quien ella ha contratado, y del que prescindirá al percatarse de que no ha resuelto su problema. La escena, invadida por el color blanco que caracteriza visualmente al filme y que connota, simbólicamente, el carácter terapéutico, no puede ser más explícita: el joven practica un acto de onanismo en el que se muestra totalmente ajeno a la presencia de Laura, no la interpela ni le presta la más mínima atención. Incluso, momentos antes, cuando ella, por voluntad propia, había decidido entablar conversación y preguntarle por el significado de los tatuajes de su cuerpo, él se resiste a proporcionar una información que considera demasiado íntima, limitándose a decirle que son partes de un libro y que está escrito en polaco.

\subsection{La fantasía, la sexualidad y el inconsciente}

Resulta evidente, en este arranque del filme, que Laura va a necesitar algo más que observar una simple escena sexual y, por ello, decide contactar con Hanna, una mujer transgénero que le proporcionará un marco más apto para la terapia. Hanna es más proactiva, se interesa por su clienta, establece un clima de confianza, le relata sus experiencias vitales y, además, le habla de la relación con su cuerpo. En su primera sesión, se muestra sociable, empática e interesada y siente curiosidad hacia su clienta: no solo le habla de su vida, de su padre músico, y de su cuerpo, le pregunta a Laura qué es lo que quiere y cómo se siente. También le expresa su agrado, cuando se percata de que va a poder satisfacer, al mismo tiempo, la fantasía voyerista de Laura y la suya propia de carácter exhibicionista: una fantasía de peep show en la que Hanna se sitúa como espectáculo del deseo de imaginarias miradas masculinas que, desde distintos ángulos, observan su cuerpo mientras se desnuda (F4).

La breve performance de Hanna se produce en un escenario que, invadido nuevamente por el color blanco y con una puesta en escena absolutamente carente de música y de iluminación, reduce al mínimo el elemento espectacular. Éste, que es sustituido por la palabra de Hanna verbalizando la escena, únicamente se percibe visualmente por el cuerpo que se muestra y la 
mirada voyerista de Laura. En términos estrictamente de puesta en escena y de montaje, nada queda, en este caso, de esa retórica -tan recurrente en el cine hegemónico- que espectaculariza, sensualiza y erotiza el cuerpo femenino. A esto se suma el hecho de que Laura es, de facto, más que una simple mirona: Hanna no se siente ajena a su presencia, no solo comparte con ella su fantasía de to-be-looked-at-ness -"ser-mirada-idad” (Mulvey, 1988, p. 10)- sino que, mientras se desviste, le hablará de la "verdad" de su cuerpo, como ella misma afirma. Un cuerpo que desafía el binarismo sexual en tanto se muestra, en sí, como un cuerpo híbrido, signado por la biología ("This is the whole truth", le dice Hanna a Laura, haciendo alusión a su sexo masculino) pero atravesado, al mismo tiempo, por la cirugía ("This is Gusti... and this is Lilo" -le cuenta más tarde a Laura, en referencia a sus pechosLilo had an operation. Lilo was no there before. Gusti was”).

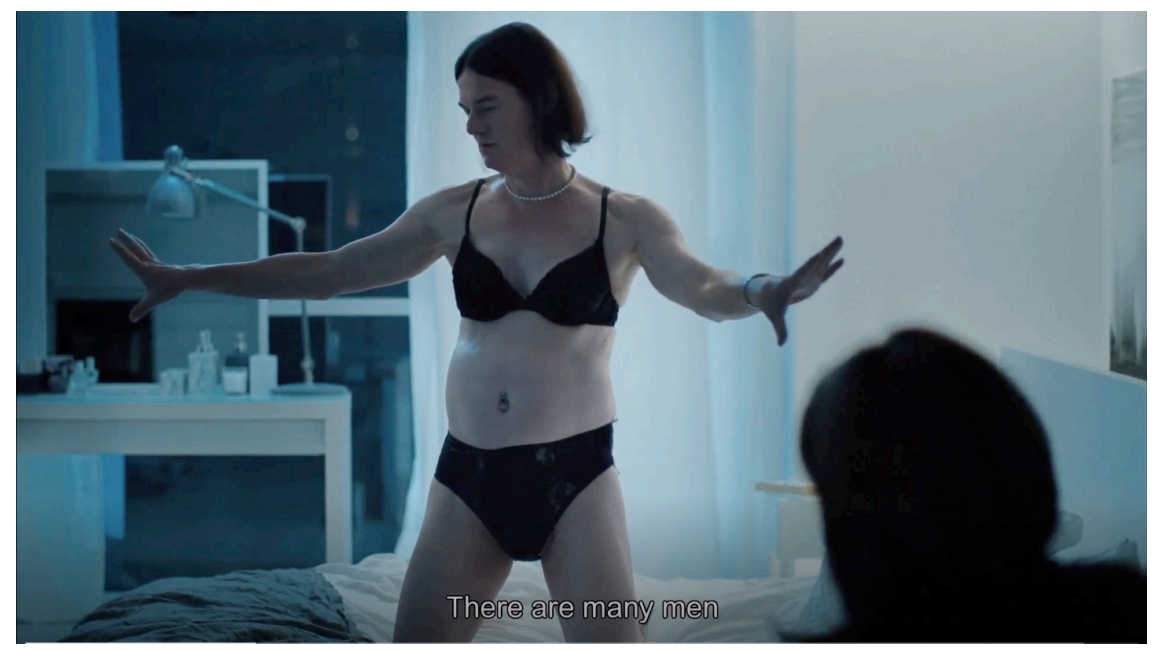

F4. Adina Pintilie, Touch Me Not (2018)

En una secuencia posterior, como hemos avanzado, Adina le cuenta a Laura que ha tenido un sueño que le perturba: la directora está en la cama con su novio y, de repente, se da cuenta de que su madre está allí con ellos y que, además, está desnuda. Intenta una y otra vez expulsarla del lecho, diciéndole que debe irse, que ese no es su lugar, pero la madre reaparece -esta vez en la puerta del balcón y le dice que no quiere estar sola. Retomamos, en este punto, las primeras palabras que Adina ha pronunciado en el filme, las cuales adquieren a partir de esta secuencia una nueva significación, en tanto parecen ahora estar claramente dirigidas hacia su madre: "Why haven't ever 
you asked me what is this film about? And what haven't I ever told you, anyway? What is our silence, comfortable agreement not to talk about it?" Adquiere también un sentido más evidente la conexión que tanto la protagonista como la directora establecían en su primera entrevista entre sus respectivos problemas, la represión y la función del inconsciente: ambas buscan respuestas a algo que les inquieta y localizan el origen de un posible trauma en una etapa pre-lingüística.

Dos cuestiones importantes -ampliamente debatidas por el psicoanálisis y la teoría fílmica feminista- emergen en Touch Me Not en relación con el planteamiento de estas secuencias. La primera de ellas tiene que ver con la idea de que existe una conexión entre la sexualidad, la fantasía y el inconsciente. La segunda, se plantea la vinculación entre fantasías privadas y fantasías públicas que la práctica representacional -en este caso, el cine, pero también la performance- pone a nuestra disposición.

La aproximación que Touch Me Not esboza en torno a la fantasía aborda ambos planteamientos: por una parte, la fantasía entendida como un proceso psíquico del sujeto individual (la visión del psicoanálisis) y, por otra, la fantasía del sujeto social cuyo deseo está estructurado por las formas públicas de la fantasía, por los discursos, las prácticas y las representaciones socialmente compartidas. En las dos secuencias referidas anteriormente se establece una conexión entre la sexualidad y la fantasía, pero mientras la primera de ellas evidencia una fantasía consciente y colectiva, la segunda revela una fantasía inconsciente (generada en el sueño) e individual.

El filme de Pintilie parece reconocer la importancia otorgada al inconsciente en la teoría de la sexualidad de Freud. Un aspecto fundamental que ha sido puesto de relieve por Laplanche y Pontalis en uno de los textos que, como bien nos recuerda Teresa de Lauretis (1994), ha animado el debate sobre la fantasía y el proceso espectatorial en la teoría cinematográfica7: "Fantasy and the Origins of Sexuality" (1968), donde ofrecen un acercamiento profundo a la noción de fantasía, entendida como la base de la sexualidad humana y de los procesos psíquicos que estructuran nuestra subjetividad. Según los

\footnotetext{
7 Véase, al respecto, las conexiones que De Lauretis establece entre el texto referido de Laplanche y Pontalis y la teoría de la espectatoriedad en Stephen Heath o Elisabeth Cowie.
} 
autores, se trataría de una escena imaginaria en la que el sujeto se coloca como protagonista y en la que se representa la realización de un deseo que es, en última instancia, un deseo inconsciente. Aunque ambos autores apuntan cómo la fantasía en la obra de Freud se presenta en distintas modalidades fantasías conscientes o sueños diurnos, fantasías inconscientes o subyacentes y fantasías originarias (la escena primaria, la seducción y la castración ${ }^{8}$ rechazan la separación formal entre ellas, señalando que en "la problemática freudiana de la fantasía no solamente no permite efectuar una distinción de naturaleza entre fantasía inconsciente y fantasía consciente, sino que tiende más bien a señalar sus analogías, sus estrechas relaciones, los pasos entre ellas" (Laplanche y Pontalis, 2004, p. 141).

Por su parte, la escena compartida por Hanna y Laura, aunque situada en un espacio privado, remite también y de forma indudable, a una fantasía socialmente compartida (objeto de deseo/sujeto de la mirada), una fantasía recurrente en la sociedad patriarcal (y en el cine comercial) que, sin embargo, aquí aparece intencionadamente alterada: la fantasía es la de Hanna, el objeto de deseo, una mujer transgénero con un cuerpo no normativo. Como hemos avanzado, la performance que ejecuta acaba transgrediendo los parámetros espectacularizantes que funcionan en la fantasía heteronormativa y patriarcal, socialmente compartida y hegemónica. Por su parte, el sujeto de la mirada no es masculino y no detenta el poder. La voyeur es otra mujer, Laura, un sujeto connotado por la vulnerabilidad, con problemas con su sexualidad y su cuerpo, un sujeto que necesita ayuda y que se encuentra sometido a la terapia. Alguien que, además, en tanto acaba siendo interrogada e interpelada por Hanna, no ocupa la posición de seguridad del voyeur, de aquel que puede mirar sin ser visto.

\footnotetext{
${ }^{8}$ Este tipo de fantasías, en la teoría freudiana, tienen un carácter universal, se encuentran generalmente en todos los seres humanos y son transmitidas filogenéticamente. Laplanche y Pontalis las describen del siguiente modo: "En la escena originaria se representa el origen del sujeto; en las fantasías de seducción, el origen o surgimiento de la sexualidad; en las fantasías de castración, el origen de la diferencia de los sexos" (2004, p. 145).
} 


\section{La política del cuerpo}

\subsection{Cuerpo y biopoder. La hipótesis productiva}

Frente a la hipótesis represiva, a la que Michel Foucault alude en el volumen I de la Historia de la sexualidad (1998)9 , refiriéndose a la teoría de Freud, el filósofo francés plantea la "hipótesis productiva": la sexualidad como construcción social, como producto discursivo de prácticas institucionales y de tecnologías de poder/saber. El distanciamiento que el filósofo francés plantea respecto al psicoanálisis sitúa la reflexión sobre la sexualidad en otra dimensión, que no es la del sujeto psíquico freudiano sino la del sujeto social. $\mathrm{Al}$ enfatizar el fenómeno histórico y cultural, las convenciones sociales que acaban produciendo al sujeto, entendido como aquel que responde a la interpelación y acepta la identidad sexual que le es socialmente asignada, la teoría foucaultiana deja de lado la importancia del inconsciente en el proceso de subjetivación: "the emphasis on sexuality as a historical and cultural phenomenon leaves out its effects on individuals, what we might call effects of subjectivation" (de Lauretis, 2008, p. 43).

El propio Foucault defiende que lo que está haciendo, con su teoría del biopoder, no es una teoría de la sexualidad sino una teoría del poder (lo que sitúa la cuestión en otro orden de cosas). Así, en una entrevista publicada en enero de 1977, en la que es interrogado acerca de su proyecto en ciernes sobre la Historia de la sexualidad, afirma lo siguiente: "For me the whole point of the project lies in a reelaboration of the theory of power. I'm not sure that the mere pleasure of writing about sexuality would have provided me with sufficient motivation to start this sequence of at least six volumes, if I had not felt impelled by the necessity of re-working this problem of power" (Gordon, 1980, p. 187).

Siguiendo la argumentación de Teresa de Lauretis (2008) aunque las visiones freudiana y foucaultiana sobre la sexualidad quedan referidas a proyectos teóricos diferentes, no son incompatibles o excluyentes entre ellas. La autora defiende la necesaria articulación entre ambas para comprender el

9 Originalmente publicado en 1976. 
fenómeno psicosocial de la sexualidad en su complejidad, es más, propone que solo cuando se combinan las dos se puede delinear una teoría materialista del sujeto sexual. Para Freud la sexualidad no es innata sino pulsional, exógena y originariamente polimorfa. Su implantación en el cuerpo del sujeto se produce en edades muy tempranas (previas, incluso, a la adquisición del lenguaje). Su dimensión específica, en la edad adulta, residiría en una representación mental de objetos (incluido el propio cuerpo) y/o escenas de fantasía que, como hemos visto, pueden ser conscientes o inconscientes (en el caso de haber sido previamente reprimidas, se mantienen como una huella mnémica imposible de recordar). Para Foucault, el cuerpo es entendido como un efecto discursivo de la "tecnología del sexo" $y$, en este sentido, la sexualidad sería un efecto del biopoder, de los dispositivos, saberes y prácticas que penetran en el cuerpo del sujeto social. Como señala de Lauretis (2007, p. 207):

while Foucault (...) describes the discursive practices and institutional mechanisms that implant sexuality in the social subject, Freudian psychoanalytic theory describes the subjective or psychic mechanisms through which the implantation takes, as it were, producing the subject as a sexual subject.

El texto fílmico de Pintilie parece articular ambas aproximaciones a la cuestión de la sexualidad. Si las referencias a conceptos claramente situados en la reflexión psicoanalítica están presentes en las secuencias anteriormente analizadas, la consideración de la sexualidad en su vertiente social e histórica, en el sentido que indica Foucault, se explicita en otros momentos del filme, en los que se alude a la forma en que la sexualidad ha sido construida, tolerada, prohibida, estigmatizada o perseguida en función de su mayor o menor acomodo a una norma social. Así, en una de las sesiones con Laura, cuando Hanna defiende la idea de que ningún tipo de práctica sexual que no atente contra la vida física o psíquica del otro o de uno mismo debería estar prohibida, está haciendo una clara alusión a los mecanismos y las tecnologías de control propias de la sociedad disciplinaria. En otra significativa secuencia, en la que Christian reflexiona con Tudor acerca de la 
distinción entre lo que está bien y lo que está mal, cuestiona la naturalización de dicha dicotomía, apuntando hacia el carácter histórico-social y construido de nuestros parámetros éticos, estéticos y morales.

\subsection{Reivindicar el cuerpo: "you are your body"}

La reflexión en torno al cuerpo, el propio y el ajeno, es una constante en el filme. Pintilie pone en escena y desnuda ante la cámara tanto cuerpos normativos como cuerpos no normativos, exponiendo un abanico de diversidades corporales que evidencian la forma en que nuestra mirada ha sido construida. Cuerpos no normativos como el de Hanna y el de Christian son mostrados con naturalidad y sin artificios ante nuestra mirada. Pero la reflexión que nos plantea el filme en torno a la política del cuerpo va más allá de una simple aceptación del mismo. Lo que plantea el filme es mucho más provocador, transgresor y político, de ahí su fuerza discursiva. No se trata solo, o especialmente, de aceptar el cuerpo sino de reivindicarlo, de reclamarlo para sí, de disfrutarlo y vivirlo como una parte integrante de la propia identidad.

De este modo, en una de las secuencias iniciales, Laura confiesa que tiene una relación problemática con su cuerpo, habla de él como si no le perteneciera, viviéndolo como pura exterioridad: "I live with my body everyday. But I suppose I don't really know it”, a lo que Adina, vinculando la identidad con el propio cuerpo, le responde: "And you are talking about your body as about a stranger. In my perception, you are your body". Esta breve escena, que justamente sucede a aquella analizada anteriormente, en la que Hanna descubre su cuerpo ante Laura y le pregunta acerca del suyo, desvela una de las tesis principales que atraviesa el filme de Pintilie: el cuestionamiento de la división cartesiana entre mente/cuerpo o espíritu/materia.

Esta reflexión se plantea en el texto fílmico con un propósito ético-político: la valoración del cuerpo, la reivindicación del placer y la sexualidad, el aprecio hacia el afecto, la sensorialidad y el encuentro con el otro. Y Pintilie lo hace trayendo a colación una idea que ha atravesado el pensamiento moderno en 
torno al cuerpo, una idea que Judith Butler analizaba en su libro Los sentidos del sujeto (2016). En su estudio sobre la obra de Descartes, Butler recupera un pasaje del filósofo francés, que se encuentra al principio de las Meditaciones, en el que éste plantea su escepticismo hacia la realidad corpórea, introduciendo la duda hacia la existencia misma de su propio cuerpo y estableciendo una separación entre lo que está unido.

La duda de Descartes sobre lo corporal -que no es sino el intento vano, como defiende Butler, de querer pensar la mente al margen del cuerpo- le lleva a establecer esa separación, una división que conlleva, en última instancia, una primacía de la mente (o del espíritu) sobre el organismo viviente, sobre nuestro propio cuerpo. Dicho con otras palabras, ese dualismo que construye la teoría cartesiana acaba primando el ámbito mental sobre el material: la duda de Descartes se dirige hacia la existencia misma de su cuerpo, pero no hacia el hecho de que él mismo es quien piensa y duda, con lo que el dualismo que propugna acaba colocando la identidad en un lugar problemático, según Butler, al intentar separar lo que, en realidad, se encuentra intrínsecamente unido.

En el filme, la separación entre cuerpo y mente es puesta de relieve cuando el personaje de Christian confiesa haberse sentido como una mente sin cuerpo que otros llevaban de un lado para otro hasta que descubrió el placer de la sexualidad: "In my childhood (...) sometimes I felt that I'm a brain being carried around without any body. And that was the state of my mind until I really came in touch with the pleasure of sexuality" El personaje de Christian cuestiona el dualismo cartesiano, la idea racionalista que sustenta la superioridad de la mente por encima del cuerpo y, al hacerlo, subraya la relevancia de la vivencia holística. Como ha señalado Asun Pié (2012), la superación de la lógica cartesiana implica una restitución del lugar simbólico que el cuerpo ocupa. 


\section{Conclusión. Función socioeducativa del cine, corporeidad e interdependencia}

Como hemos visto a lo largo del artículo, Touch Me Not plantea la necesaria combinación entre dos tipos de sujeto que, en realidad, se encuentran indisolublemente unidos: el sujeto sexual del psicoanálisis y el sujeto social derivado de la teoría foucaultiana. Estos dos sujetos se encarnan en los cuerpos de los personajes, que nos interpelan una y otra vez, haciéndonos partícipes de sus relatos, sus fantasías, sus frustraciones, sus experiencias y sus vidas.

Podemos concluir que Touch Me Not se plantea también como un cine socioeducativo, una herramienta de concienciación social que apunta hacia una pedagogía basada en la importancia de la corporeidad, la alteridad y la interdependencia. El lugar desde el que Pintilie nos interpela se explicita en distintas secuencias en las que, como hemos visto, se cuestiona la transparencia enunciativa y se aboga por evidenciar que estamos ante un objeto fruto de la producción discursiva. Desde ese lugar se espera que participemos del relato fílmico, que nos impliquemos emocional e intelectualmente. El mensaje socioeducativo hacia los espectadores queda expresado por Christian quien, dirigiéndose a Grit (su pareja en la vida real) y también a los espectadores, rompe la cuarta pared explícitamente ("I think we have an audience") y, cuando Pintilie le pregunta por qué les ha permitido acercarse tanto a su vida, a su intimidad, manifiesta su deseo de cambiar la mentalidad de las personas: "I feel I really hope that I can change people's perspective".

Pero hay algo más que el filme plantea: la vulnerabilidad es una condición de todo ser humano. Christian necesita de la ayuda de los otros para moverse pero su condición vulnerable -aquella que nos interpela la primera vez que lo vemos en la pantalla- no eclipsa la simbiosis de esa terapia del tacto que lleva a cabo junto a su compañero. Una terapia que parece estar tanto o más orientada hacia el sujeto a quien Christian está ayudando, hacia el cuerpo más normativo de Tudor, que es quien tiene verdaderos problemas para expresar sus emociones y relacionarse con los demás (F5). 


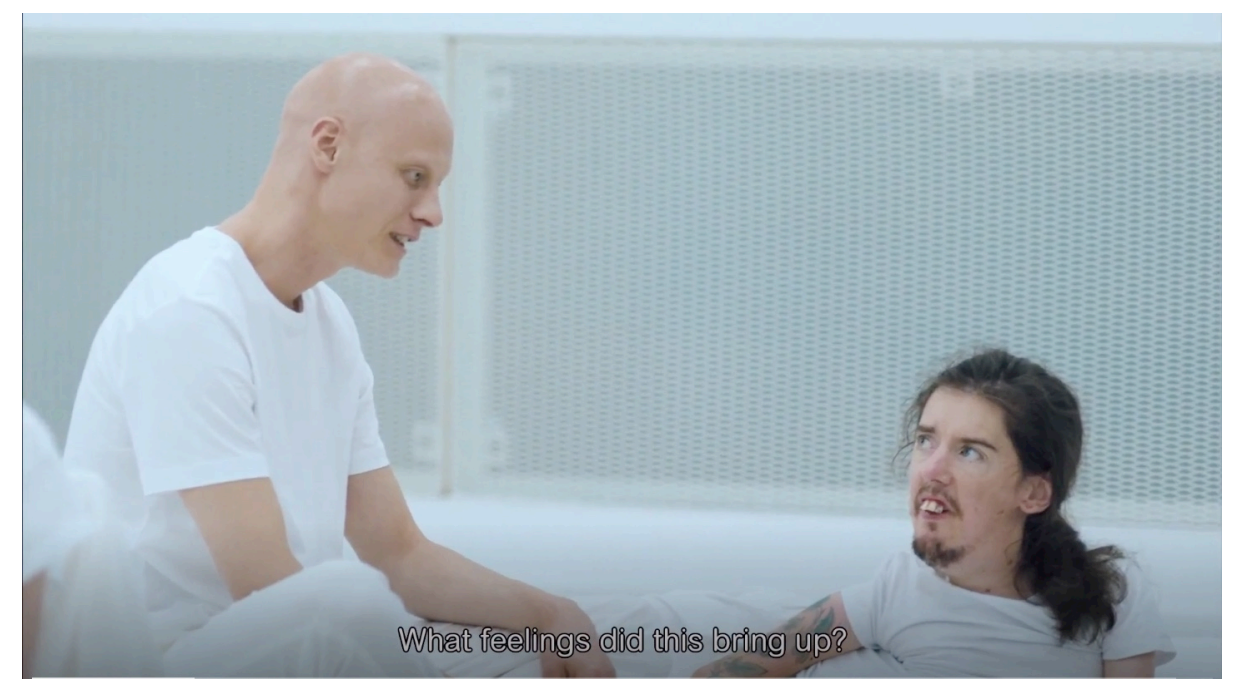

F5. Adina Pintilie, Touch Me Not (2018)

En efecto, Touch Me Not plantea una crítica a la ilusión del sujeto autosuficiente, aquel que en la fantasía de su plena independencia es incapaz de reconocer la necesidad del otro. El planteamiento de la película se acercaría, en este sentido, a una "pedagogía de la interdependencia" enfocada, como señala Asun Pié, a la recuperación de lo que nos hace humanos: "la necesidad del otro, el reconocimiento de este otro, nuestra apertura indefinida a él” (2014, p. 130). La película conectaría también con esa "corporización de la pedagogía" que reivindica la importancia del cuerpo como parte fundamental de la identidad, lo que supone "comprender el cuerpo y tratarlo ya no como la carcasa poco valiosa del alma o la mente, sino como aquello que nos constituye y nos construye en su totalidad" (Pié, 2012, p. 227). Esto implica, indica la autora, una aproximación al tema de la vulnerabilidad y la dependencia como problemas sociales y educativos, lo que se ha visto reflejado en las estrategias políticas de algunos grupos que -como podríamos afirmar del activismo real de Christian- han encontrado en "la subalternidad encarnada en modos de sufrimiento y dolor (...) un hueco a la presunción que es posible convertir la diferencia en disfrute" (Pié, 2014, p. 130).

Si bien Christian o Hanna había encontrado en sus respectivas vidas la manera de disfrutar de su corporeidad, Laura y Tudor consiguen superar, a lo largo del filme, sus respectivos problemas. La última secuencia no puede ser 
más contundente al respecto: mientras se escucha la canción "Wir sind gekommen die Geschenke abzuholen”, Laura baila desnuda, desinhibida, sin complejos, disfrutando de la belleza de un cuerpo que antes le costaba mostrar (F6). La película de Pintilie acaba con esa catarsis del cuerpo, con ese acto que alude a la curación de la terapia: la abreacción, un concepto derivado del psicoanálisis que remite a esa "descarga emocional por medio de la cual un individuo se libera del afecto ligado al recuerdo de un acontecimiento traumático, lo que evita que éste se convierta en patógeno o siga siéndolo" (Laplanche y Pontalis, 2004, p. 1). Esa celebración, ese canto al cuerpo, ese goce y esa felicidad que cierra el filme es también una declaración, un discurso que nos involucra, que se dirige a nosotros, interpelando conjuntamente a nuestro intelecto y nuestra emoción, en un cierre que parece querer recordarnos que somos, antes y por encima de cualquier otra cosa, cuerpo.

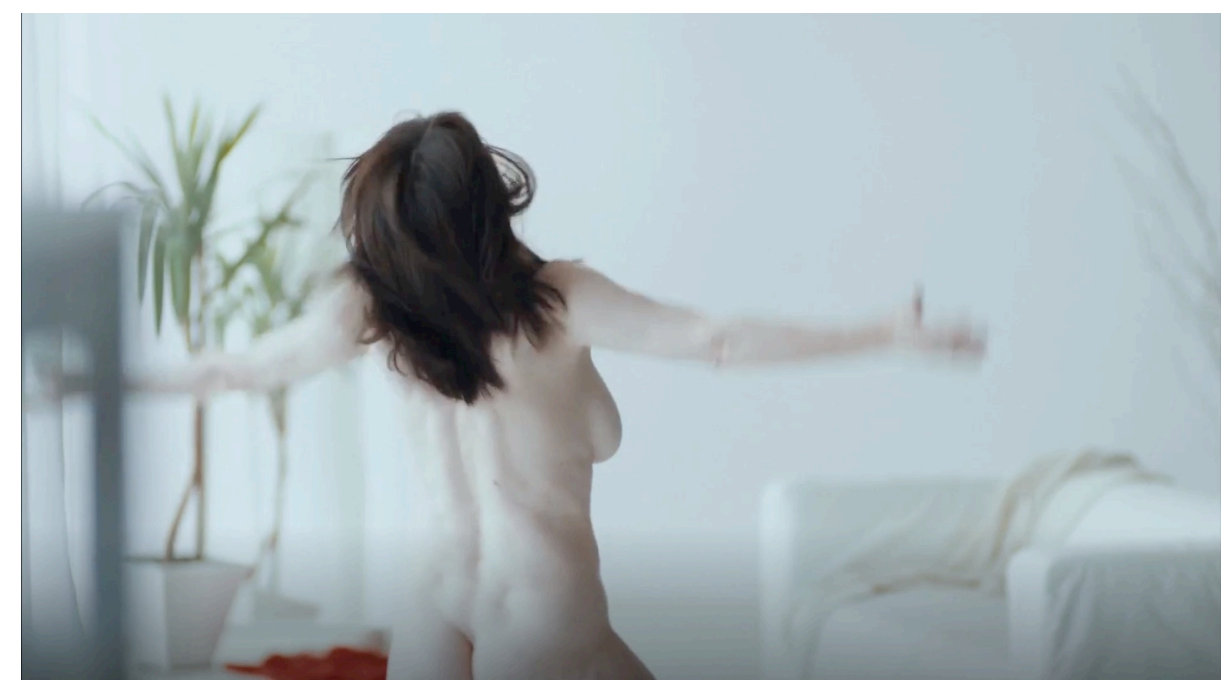

F6. Adina Pintilie, Touch Me Not (2018)

\section{Referencias bibliográficas}

Ayuso Ros, F. (2014a). La reformulación de la tradición realista en 4 meses, 3 semanas y 2 días (Cristian Mungiu, 2007). En D. Caldevilla (ed.), Lenguajes y persuasión: Nuevas creaciones narrativas (pp. 35-50). Madrid: ACCI. 
Ayuso Ros, F. (2014b). Policía, adjetivo (Corneliu Porumboiu, 2009): Deconstrucción, realismo y crisis del lenguaje. Revista F@ro, 1(19), 13-29.

Butler, J. (2016). Los sentidos del sujeto. Barcelona: Herder.

De Lauretis, T. (1994). The Practice of Love: Lesbian Subjectivity and Perverse Desire. Bloomington: Indiana University Press.

De Lauretis, T. (2007). Figures of Resistance: Essays in Feminist Theory. Urbana and Chicago: University of Illinois Press.

De Lauretis, T. (2008). Freud's Drive. Psichoanalysis, Literature and Film. New York: Palgrave Macmillan.

De Lauretis, T. (2012). Panteridad. Vivir en un cuerpo dañado. EU-topías. Revista de interculturalidad, comunicación y estudios europeos, 4, 918. Recuperado de: http://eu-topias.org/panteridad/

Foucault, M. (1998). Historia de la sexualidad. Vol. 1. La voluntad de saber. Madrid: Siglo XXI.

Gordon, C. (ed.) (1980). Power/Knowdledge. Selected Interviews and Other Writings 1972-1977. Michel Foucault. New York: Pantheon Books.

Gray, C. (2018). Touch Me Not: the Berlinale-winning Romanian film that has provoked international outrage. The Calvert Journal. Recuperado de: https://www.calvertjournal.com/articles/show/9730

Ieta, R. (2010). The New Romanian Cinema: A Realism of Impressions. Film Criticism, 34(2/3), 22-36. Recuperado de: https://www.jstor.org/stable/44019235?seq=1\#page_scan_tab_conte $\underline{\text { nts }}$

Laplanche, J. \& Pontalis, J. B. (1968). Fantasy and the Origins of Sexuality. The International Journal of Psychoanalysis, 49(1), 1-18.

Laplanche, J. y Pontalis, J.B. (2004). Diccionario de psicoanálisis. Buenos Aires: Paidós.

Marks, L. (2000). The Skin of the Film: Intercultural Cinema, Embodiment, and the Senses. Durham and London: Duke University Press.

Mulvey, L. (1988). Placer visual y cine narrativo. Valencia: Episteme.

Nasta, D. (2013). Contemporary Romanian Cinema: The History of an Unexpected Miracle. London and New York: Wallflower Press.

Nasta, D. (2016). Contemporary Romanian Auteurs: Politics, Irony, and Reflexitivy. In S. Jeong and J. Szaniawski (eds.). The Politics of Authorship in 21ts Century Cinema (pp. 159-178). New York: Bloomsbury.

Nasta, D. (2019). Beyond Modernity: the Stylistic Divide and the New Romanian Cinema. In C. Stojanova and D. Duma (eds.) The New Romanian Cinema (pp. 23-35). Edinburgh: Edinburgh University Press. 
Nichols, B. (2001). La representación de la realidad. Barcelona: Paidós.

Pié, A. (2012). Pedagogía de la interdependencia. En A. Pié (coord.). Deconstruyendo la dependencia: propuesta para una vida independiente (pp. 213-229). Barcelona: UOC.

Pié, A. (2014). Por una corporeidad postmoderna. Nuevos tránsitos sociales y educativos para la interdependencia. Barcelona: UOC.

Pop, D. (2014). Romanian New Wave Cinema. An Introduction. North Carolina: McFarland.

Popan, E. R. (2014). Recent Romanian Cinema: Is It a Real New Wave or Just a Splash in the Water?. The Communication Review, 17 (3), 217232. https://doi.org/10.1080/10714421.2014.930273

Sobchack, V. (2004). Carnal Thoughts: Embodiment and the Moving Image Culture. Berkeley and Los Angeles: University California Press.

Uricaru, I. (2019). No Melo: Minimalism and Melodrama in the New Romanian Cinema. In C. Stojanova and D. Duma (eds.) The New Romanian Cinema (pp. 50-62). Edinburgh: Edinburgh University Press.

Yao, W. (2018). Adina Pintilie and the End of Romanian New Wave. Close Up: Film and Media Studies, 2(2), 47-60. Recuperado de: https://unatc.ro/cercetare/reviste/CloseUp_2018_online.pdf. 